REPRODUCTION

\title{
Aiming towards "moral equilibrium": health care professionals' views on working within the morally contested field of antenatal screening
}

\author{
B Farsides, C Williams, P Alderson
}

J Med Ethics 2004;30:505-509. doi: 10.1136/jme.2002.001438

See end of article for authors' affiliations

....................

Correspondence to: Dr B Farsides, Centre for Medical Law and Ethics, King's College London, University of London, London, UK; bobbie. farsides@kcl.ac.uk

Revised version received 5 February 2003 Accepted for publication 23 March 2003
Objective: To explore the ways in which health care practitioners working within the morally contested area of prenatal screening balance their professional and private moral values.

Design: Qualitative study incorporating semistructured interviews with health practitioners followed by multidisciplinary discussion groups led by a health care ethicist.

Setting: Inner city teaching hospital and district general hospital situated in South East England.

Participants: Seventy practitioners whose work relates directly or indirectly to perinatal care.

Results: Practitioners managed the interface between their professional and private moral values in a variety of ways. Two key categories emerged: "tolerators", and "facilitators". The majority of practitioners fell into the "facilitator" category. Many "facilitators" felt comfortable with the prevailing ethos within their unit, and appeared unlikely to feel challenged unless the ethos was radically challenged. For others, the separation of personal and professional moral values was a daily struggle. In the "tolerator" group, some practitioners sought to influence the service offered directly, whereas others placed limits on how they themselves would contribute to practices they considered immoral.

Conclusions: The "official" commitment to non-directiveness does not encourage open debate between professionals working in morally contested fields. It is important that practical means can be found to support practitioners and encourage debate. Otherwise, it is argued, these fields may come to be staffed by people with homogeneous moral views. This lack of diversity could lead to a lack of critical analysis and debate among staff about the ethos and standards of care within their unit.
$\mathrm{P}$ ractitioners who work in the morally contentious area of prenatal screening for fetal anomalies confront many issues which could give rise to moral conflict. They may be forced to consider the rights and wrongs of abortion; the nature of the maternal fetal conflict; the question of when serious disability might be incompatible with a reasonable quality of life, and the complex issue of establishing the moral status of the fetus. While they work closely with the woman carrying the fetus, these practitioners also work with the human fetus very directly-for example, during ultrasound scanning. They are also sometimes required to contribute to a process which will ultimately lead to its destruction. ${ }^{1-3}$

The principle of non-directive counselling is seen as a "universal norm" in relation to prenatal screening, with only the clients' values being discussed and practitioners' views being deliberately excluded. ${ }^{4}$ Clarke ${ }^{5}$ describes a non-directive approach as:

...not to lead clients to make particular decisions or choices (those preferred or recommended by the clinician, the health service or by society) but to help them to make the best decisions for themselves and their families as judged from their own perspectives.

There are debates in the literature, however, not only about the desirability and feasibility of the non-directive approach, ${ }^{6}$ but also about other motives which might lie behind the ethos of non-directiveness, apart from a respect for client preference. Clarke, for example, also highlights key reasons why non-directiveness is seen as so important in the area of genetics. These include a strong desire to dissociate the area of genetics from the recent history of eugenics, and the protection of health professionals, by ensuring that professionals will not be held legally accountable for decisions taken by clients.

The centrality of informed choice in this area is also illustrated by the foreword to the Second Report of the UK National Screening Committee, ${ }^{7}$ which states that a key theme is:

...the need to be absolutely clear and explicit about the risks and limitations of screening. There is a responsibility to ensure that people who accept an invitation do soon the basis of informed choice.

Again, research indicates the many difficulties inherent in achieving informed choice in the antenatal area. These include the lack of balanced information about "screened for" $^{\prime \prime}$ conditions $^{89}$ and the fact that higher rates of screening are achieved when a test is offered as part of a routine antenatal visit, ${ }^{10}$ partly because the very offer of a test can be seen as a recommendation. ${ }^{11}$

Despite these difficulties, the concepts of non-directive counselling and informed choice continue to underpin-at least theoretically — professional attitudes to offering prenatal screening. Again, in theory, this indicates that the practitioner allows the client to define the moral boundaries and to determine the scope of clinical activity. ${ }^{6}$ To allow this, health care professionals would have to be both willing and able to exclude their own moral views from their professional interactions. Alternatively, they could attempt to incorporate their own moral views into their professional roles in ways that respect several potentially conflicting values-for example: practitioners' own values; the clients' values; the 
permissive value of informed choice, and culturally varying values. Some of these values are prescriptive, some are permissive, and some are precisely defined whereas others are vague or contested. Inevitably values conflict, leaving practitioners in the difficult position of trying to reconcile them all in some kind of "moral equilibrium". Supporting this, professional guidance for practitioners clearly states that private moral values should not affect the care of patients. The General Medical Council's publication, The New Doctor states-for example: "In particular, as a doctor you must make sure that your personal beliefs do not prejudice your patients' care" ${ }^{\prime 12}$ This immediately makes it difficult for the practitioner who has absolute moral objections to a particular practice that is generally accepted as a standard procedure. Antenatal screening for fetal anomalies-for example, has become inextricably bound up with the offer of termination of pregnancy, and therefore a health care professional opposed to termination of pregnancy would need to reflect upon their participation in the field. It is of interest to note here that Bill Liley, considered by many to be the founder of fetal medicine, was also a founder member and the first president of the Society for the Protection of the Unborn Child. ${ }^{1}$ Fetal medicine has, however, developed in directions that Liley could not have condoned given his absolutist position.

In English law a health care professional is afforded the legal right to conscientiously object to participating in terminations of pregnancy, so technically people could opt for a career in obstetrics or midwifery, while protecting themselves against personal involvement in what they consider immoral practices. As with any form of conscientious objection, however, one is not afforded the right to distinguish between acceptable and non-acceptable forms of the act, and to desist from the latter. Rather the objection must be to the act as such, irrespective of particular circumstances. Thus, one would be required to abstain from all terminations, which could be a difficult position to negotiate with professional colleagues. At a personal moral level one would also need to define for oneself what counts as an action contributing to the performance of a termination.

This paper reports one aspect of an innovative research project which attempted to "bring ethics into the hospital", partly in order to explore how practitioners address questions about genetics and ethics which affect their work. The paper focuses on practitioners' explanations of how they balanced their professional and private moral values while working within the area of prenatal screening.

\section{METHODS}

Following ethics committee approval, 70 people working in two English hospitals (a teaching hospital and a district general hospital) and in the attached community services, were interviewed individually by the two research sociologists (PA and CW). The semistructured "guided conversations $^{\prime \prime 13}$ encouraged respondents to give their own accounts and meanings. The interview themes included interviewees' views about antenatal screening, their moral beliefs and values, and about how these affected their daily work.

The majority of those interviewed then took part in small (mainly 4-6 participants) multidisciplinary discussion groups facilitated by a health care ethicist (BF). The 11 groups discussed topics raised during earlier interviews. Most of the participants in the groups worked in areas which related either directly or indirectly to various aspects of perinatal care, and included: midwifery managers and midwives; health visitors; ultrasound scanners; obstetricians; fetal medicine specialists; haematologists; paediatricians; haematology counsellors; genetic counsellors, and psychologists. In broad terms, the 56 group participants consisted of 20 midwives, 20 doctors, and 16 others from a variety of disciplines. Discussions lasted approximately two hours, and with permission, were taped and fully transcribed.

Transcripts were analysed by content for emergent themes ${ }^{14}$ which were then coded. ${ }^{15}$ Codes were compared for similarities and differences across the groups, eventually leading to broader themes which made up the overall theoretical framework. ${ }^{16}$ The research team met frequently to discuss the data and analysis and to incorporate sociological and philosophical perspectives. To protect anonymity, each practitioner is identified by a number. Participant titles have been purposely kept broad, so-for example, practitioners described as obstetricians range from research fellows to consultants, and include those specialising in fetal medicine.

\section{FINDINGS}

It was apparent from the data that practitioners managed the interface between their professional and private moral values in a variety of ways, and that the moral views of an individual practitioner could have an impact upon their practice. Two key categories emerged, which we have labelled "tolerators" and "facilitators". Tolerance is defined here as the willingness to accept what is seen as a wrongdoing by another, and maybe even to assist them in their perceived wrongdoing. The term "facilitator" indicates a willingness and ability in these practitioners to separate their own moral views and their professional duties to the extent that the moral limits they operate within are almost completely externally defined. Furthermore, it was found that a category often discussed within applied ethics literature, that of "absolutist", was not represented within our sample, and the possible reasons for this will be discussed first.

\section{Practitioners as absolutists}

For our purposes, absolutism entails having a moral belief about something which is fixed and non-negotiable. So, if something is seen as wrong, it will be wrong in all cases. This view is usually accompanied by the belief that this thing ought not to be allowed to happen. So-for example, if one believes the fetus has a moral status which entitles it to an inalienable right to life, one might also believe that under no circumstances whatsoever should direct action be taken to end the life of the fetus. This belief would translate into a complete prohibition on abortion. Conversely, if one believed that the paramount right was the right of a woman to control her body and her fertility, one might claim that her right to terminate a pregnancy should not be bound by law or conventions of practice.

Given the current situation in which very few of the fetal conditions screened for during pregnancy can be successfully treated, the choices open to women are generally to continue the pregnancy or to terminate it. This being the case, the person holding an absolute objection to termination of pregnancy would probably have to decide that this area of health care provision is not one that they can embrace. Indeed, the absolutist view was not articulated either in the protected environment of a one to one interview, or within the group discussions. However, some practitioners talked about how they had avoided specialising in areas such as obstetrics, which they knew would result in a conflict between their professional and private values:

Paediatrician, 58: When I was a medical student...I never went to theatre when they did an abortion, and I would never have become an obstetrician because it would have put me in a completely untenable position personally to do that (practising Roman Catholic). 
Radiographer, 49: If I had practised obstetrics or gynaecology then transfusion and termination are part of the work there, and it would have caused a lot of confusion and upset for me...I would then have had to have double standards, one in my job and one in my religion, which is in no way possible... but now I am happy because this work is not really in any way contradicting the Bible's principles (Jehovah's Witness).

For these practitioners, the potential for moral conflict was too great to allow them to choose a particular professional path. Neither, however, took the strong absolutist position of demanding that the practices they consider morally unacceptable be disallowed.

\section{Practitioners as tolerators}

As previously stated, tolerance is defined here as the willingness to accept what is seen as a wrongdoing by another, and maybe even to assist them in their perceived wrongdoing. This is not because one is indifferent, or because one cannot be sure that the act is wrong, but rather because one believes there is a greater virtue in allowing others to exercise their autonomous choices. Tolerance is most interesting when combined with moral commitment. So-for example, one might believe that while it is definitely morally wrong to abort a fetus on the basis of a relatively minor anomaly, because of a commitment to respecting the autonomous choices of the woman, this must be allowed to happen. This category was well represented within our sample, but within the category there were some interesting variations. Some practitioners came closer to the absolutist position, wishing to demarcate clearly the limits of their tolerance. These limits operated in two quite different ways.

Firstly, a number of practitioners felt that a line should be drawn around the conditions for which termination of pregnancy should be offered within a screening service. One senior manager (42) stated-for example:

I do believe there's a risk that screening goes too far. You cannot terminate, really, I don't think, for things like cleft lip and palate, unless it really is going to lead to some sort of psychological problem. I wouldn't personally define that as a major abnormality, it's correctable, so is talipes.

Similarly, an obstetrician (44) spoke of the detection of mild fetal kidney problems during routine antenatal scans, which in the majority of cases turned out to be insignificant:

Now you could have a couple in front of you who say, "Well, I don't want my baby to have any risk of this, I want a termination because of it". You say, Fine, you can do whatever you want to do, but you can't do it in this hospital".

Such practitioners only remain within the tolerator category for as long as they are willing to accept that the service engages in practices they consider wrong. The extent of their tolerance is measured in terms of how far beyond what they consider to be morally acceptable they are prepared to go. Few would argue that a commitment to respect for individual autonomy entails a commitment to unfettered tolerance. The interesting question becomes that of how to define and impose the limits.

In contrast, other practitioners did not seek to influence the service offered directly, but instead placed limits on how they themselves would contribute to practices they considered immoral. They knew their own moral views and were aware that these were in conflict with some of the moral positions integral to the screening process. They had no desire, however, to alter the terms on which screening was offered. In moral philosophy terms they were broadly tolerant but wished to "keep their own hands clean". A midwife (45) stated-for example:

I come from a Christian background...I don't agree with abortion and things like that, but especially with prenatal screening tests, you have to give that woman information because that's what the tests talk about [that is, the option of having an abortion if an anomaly is found], and regardless of my religious belief or my Christian belief, I still have to give that information.

When asked if there were any conflicts between her personal and professional values, she went on to say:

Yes. Well, I guess it doesn't boil down to a big problem personally. Stuff like going to get prescriptions, or giving women drugs that will terminate their pregnancies. I said, "Well, I have no problems looking after these women but I will not administer the drug, I will not do certain things", because that just overstretched the boundaries...

Similarly, a sonographer (49) said:

I'm a Jehovah's Witness so I don't believe in doing terminations. It's up to the parents to discuss it with the consultants. I don't scan with the intention of making a decision towards termination or against termination, I just say something is normal or abnormal, the baby is well or not so well. I really don't scan people to make the decision... Anything beyond that, even if they ask me whether it's possible to have the baby terminated, I say, "you have to speak to the doctor because I don't make that decision", and I don't say anything for or against termination.

This latter position of "keeping one's own hands clean" could be seen as more tolerant than those who wish to place limits upon what is offered, in the sense that it need not necessarily impact upon the range of choices available to women. These practitioners have no wish to limit the choices available to women, but do wish to abstain from those practices with which they disagree. Some would argue that such a position is inconsistent, and absolutists would certainly challenge such a position when held by people who shared their core moral objection to the practice in question. How, they would ask, can one be part of a system which engages in immoral acts, even if one is not directly involved in their execution?

To some extent all practitioners involved in prenatal screening face conflicts between their personal values and professional duties, some rarely, some more frequently. Some are more aware of such conflicts than others. Practitioners with broadly tolerant personal values are likely less often to need to consider such conflicts than those who incline towards more strict or absolute moral codes. For them, a recurring question is how to respect their patients' values while remaining true to their own moral views, which they experience as too intrinsic to their identity to be able to "leave at home".

\section{Practitioners as facilitators}

The majority of practitioners fell into the category defined here as "facilitators", and once again, there were variations. 
In defining facilitators we would point to their willingness and ability to separate their private moral views and their professional duties to the extent that the moral limits they operate within are almost completely externally defined. Ostensibly this meant that their workplace choices were made with reference to the ethos of the unit within which they worked, and the moral views of the clients they worked with. They claimed their own moral views played no part in establishing the moral parameters of their professional practice:

Genetic counsellor, 63: I don't let my religion guide me in my work. I take it as my own personal thing...I would take people's religious beliefs into consideration when I am doing work and when I'm counselling of course, but my own personal beliefs, I don't at all.

Health visitor, 56: I just think if you can't stand the heat get out of the kitchen...you have to be able to keep your opinions to yourself. I mean, I come across things and I think, "Goodness, that lady's using termination as a method of family planning", and however much I don't agree with that, that's obviously fine, or else she needs some help, but you just have to keep that to yourself. You can't moralise to people about what they're doing, or their behaviour, you can only offer help to them.

Many practitioners appeared to be implicitly importing the moral view that the woman's right to choose is paramount, and were convinced that was entirely appropriate. Thus they found their approach to be in step with the ethos of their institution, and at this level they avoided conflict. Some did feel, however, that this commitment could lead to women making choices they believed to be morally inappropriate. They dealt with this by discounting the relevance or significance of their own moral views, as illustrated by the following quote:

Chaplain, 68: ... there are set rules and regulations about what the Trust expects of us, that we support the parents. There are set rules and regulations about when abortion is legal, when it's not, and it's kind of-I don't buck the system in that sense. I don't kick against the system, I kind of operate within it, and that's a much easier position to take I'm sure.

As long as a practitioner is comfortable with the prevailing ethos within their unit, they are unlikely to feel challenged about whether or how they ought to separate their personal and professional moral values. Indeed, they need not do so unless the ethos of the workplace is radically challenged. An example of this occurred in one of the hospitals, where a decision had been taken to inform pregnant women of the sex of their fetus, if this information was requested. Initially, one primary care manager was articulate in her defence of a woman's right to be given all of the relevant information to make informed antenatal choices, stating:

Manager, 53: You are either going to have to give everybody the information and assume that they've taken a responsible decision-whatever responsible is - or you don't give them anything, which feels completely against the way we are all going, and doesn't sound sustainable.

In relation to telling women the sex of their fetus, however, she said:
It is a big issue for us [the primary health care authority], we were really upset, understandably upset, that the hospital has gone down the line of telling parents the sex of the child, because of the issue for our local population...There are very difficult issues around the termination of a normal baby because it's the "wrong" sex, but we accept that the hospital has been forced to do this because other Trusts do it, but, I'm not sure-for us it's very difficult.

For other practitioners, the separation of personal and professional moral values was a daily struggle:

Chaplain, 68: I think that they [professional and private moral values] don't clash, but there is part of me that professionally doesn't show itself within the situations that I deal with, and so that's the bit of me that I take home, that's the bit of me that gets upset...

Midwife, 48: Even though I am quite a feminist, I still have quite a bit of religious background that comes into play. I am a Rastafarian, so life is very sacred to us, that comes into play, but then because I am a feminist I would also balance it out by giving a woman choice...I try not to get that involved with my work because if I instilled (sic) my personal views on others, it would be, "Oh no, don't have that done" and so on.

One obstetrician (11) clearly prioritised the woman/ couple's right to choose, stating:

I think what I feel personally is irrelevant to the-you know, you give the information to the parents and one has to respect what they think about it. I mean, there are a number of things that obviously on a personal level-when people don't want a baby with a cleft lip or whatever-I know I personally don't agree with it, but it's not for me to say...

Later in the discussion group, however, she indicated some of the personal costs to herself, saying:

From my point of view, although I do it because it's fetal medicine, I hate the idea that I'm only doing what I do to offer people terminations, and some weeks I go home and I feel so miserable because all I've done are terminations...

A quote such as this highlights a dilemma faced by us as researchers engaging with practitioners. On the one hand we asked them to tell us how they confronted the moral complexities and potential conflicts within their professional lives. On the other hand we felt a responsibility towards them as individuals, which raised questions in our minds about the possible destabilising effect of our work. Over time we hope that we succeeded in striking a balance between our wish to challenge and explore, and our wish to support and help develop reflective practice in the field. Certainly practitioners' evaluations of the seminars indicated that the majority valued the coherent discussion of many pressing issues, which addressed important though seldom discussed ethical questions. They were also relieved to discover that colleagues shared both the anxieties and the uncertainties that they struggled with as individuals. ${ }^{17}$ 


\section{CONCLUSION}

It is important that the current policy emphasis on nondirectiveness and informed choice in the context of antenatal screening does not lead to false assumptions about an underlying homogeneity of moral views among health care professionals. Our previously published research indicates that the "official" commitment to non-directiveness and the consequent demand that practitioners conceal their own opinion does not encourage open debate about where people stand, and what it entails for them to act professionally, given their personal views. ${ }^{17}{ }^{18}$ Many of the health care practitioners attempted to adhere to the requirements of the non-directive approach, despite holding moral views which made it difficult to accept some of the choices offered to women. The position of these professionals needs to be recognised, and the costs they bear need to be acknowledged. Although the final decision ultimately lies with the woman, the practitioner inevitably plays a part in the choices made, and may have to face the difficult task of trying to "keep her own hands clean", while not compromising the care offered to clients. Even for those holding less absolutist positions, it can be seen that the existence of clearly prescribed professional duties of care prioritising non-directiveness and support for client autonomy could lead to conflicts which were difficult for individuals to resolve.

Our published work on participants' evaluations suggested that the seminars reported here offer one useful format for trusts to develop. ${ }^{17}$ In many ways, the seminars appeared to provide a unique forum for enabling practitioners to share their concerns, and to learn from one another's views and experiences. Unless practical ways can be found of supporting professionals facing conflicts of this type, it is conceivable that morally contested disciplines may come be staffed, through both staff selection and self selection, by people with homogeneous moral views. Our research indicates-for example, that absolutists have tended to opt out of this particular work area. This lack of diversity could lead to a lack of critical analysis and debate among staff about the ethos and standards of care in their unit. This debate not only helps ensure that high standards are sustained, but in addition, helps ensure that a humane, and not simply a technical, service is provided for women and their families.

\section{ACKNOWLEDGEMENTS}

We are grateful to everyone who took part in the seminars, and to the Wellcome Trust Bioethics Initiative for funding the research project
Cross Currents in Ethics and Genetics around the Millenium, 19992001, no 056009.

\section{Authors' affiliations}

B Farsides, Centre for Medical Law and Ethics, King's College London, University of London, The Strand, London WC2R 2LS, UK

C Williams, School of Nursing and Midwifery, King's College London, James Clerk Maxwell Building, London SE1 8WA, UK

P Alderson, Social Science Research Unit, Institute of Education, University of London, 18 Woburn Square, London WC1H ONR, UK

Funded by The Wellcome Trust Biomedical Ethics Programme (project no. 056009)

\section{REFERENCES}

1 Casper M. The making of the unborn patient. New Brunswick: Rutgers University Press, 1998.

2 Kent J. Social perspectives on pregnancy and childbirth for midwives, nurses, and the caring professions. Buckingham: Open University Press.

3 Williams C, Alderson P, Farsides B. Conflicting perspectives of the fetus: person, patient, "nobody", commodity? New Genet Soc 2001;20:225-38.

4 Burke B, Kolker A. Directiveness in prenatal genetic counseling. Women and Health 1994;22:31-53.

5 Clarke A. The process of genetic counselling. In: Harper P, Clarke A, eds. Genetics, society and clinical practice. Oxford: BIOS Scientific Publishers, 1997:180.

6 Williams C, Alderson P, Farsides B. Is non-directiveness possible within the context of antenatal screening and testing? Soc Sci Med 2002;54:339-47.

7 Department of Health. Second report of the UK national screening committee. London: Department of Health, 2000.

8 Abramsky L, Hall S, Levitan J, et al. What parents are told after prenatal diagnosis of a sex chromosome abnormality: interview and questionnaire study. BMJ 2001;322:463-6.

9 Williams C, Alderson P, Farsides B. What constitutes "balanced" information in practitioners' portrayals of Down's syndrome? Midwifery 2002;18:230-7.

10 Dormandy $\mathrm{E}$. Better understanding of factors influencing uptake is needed. BMJ 1999;318:805

11 Press N, Browner C. Why women say yes to prenatal testing. Soc Sci Med 1997:45:979-89.

12 General Medical Council. The new doctor. Supplement on general clinical training in general practice. London: GMC, 1998.

13 Lofland J, Lofland L. Analyzing social settings: a guide to qualitative observation and analysis [2nd ed]. Belmont: Wadsworth, 1984.

14 Weber R. Basic content analysis. London: Sage, 1990.

15 Strauss A, Corbin J. Basics of qualitative research. London: Sage, 1990.

16 Charmaz K. The grounded theory method: an explication and interpretation. In: Emerson R, ed. Contemporary field research: a collection of readings. Prospect Heights, IL: Waveland Press, 1983.

17 Alderson P, Farsides B, Williams C. Examining ethics in practice: health service professionals' evaluations of inhouse ethics seminars. J Nurs Ethics 2002;9:518-51.

18 Williams C, Alderson P, Farsides B. Too many choices? Hospital and community staff reflect on the future of prenatal screening. Soc Sci Med 2002; 55:743-53. 